\title{
Splenic rupture in a patient on antiplatelet therapy - the role of splenic angioembolization
}

\author{
Ruptură splenică la un pacient sub tratament antiagregant plachetar - rolul \\ angioembolizării splenice
}

\author{
D.P. VENTER ${ }^{1}$, Mircea BEURAN ${ }^{2}$, L. GULIE 3 , C. OPRESCU ${ }^{4}$, M. BRATU ${ }^{4}$, \\ Mircea VENTER ${ }^{4}$, Alexandru CHIOTOROIU 4
}

${ }^{1}$ Secția a 2-a Chirurgie, Spitalul Clinic de Urgență pentru Copii „Grigore Alexandrescu“, Bucureşti, România

2Departamentul X Chirurgie Generală, UMF "Carol Davila", Bucureşti, România

${ }^{3}$ Departamentul 1 Radiologie Intervențională, Spitalul Clinic de Urgență, Bucureşti, România

${ }^{4}$ Clinica Chirurgie III, Spitalul Clinic de Urgență, Bucureşti, România

\begin{abstract}
The case of a 74-year-old patient, the victim of an accidental fall, with sequelae stroke under double antiplatelet medication (Clopidogrel, Aspirin) is presented. Examination of the abdominopelvic CT with an intravenous contrast agent reveals an AAST-OIS grade III splenic rupture with active bleeding and significant hemoperitoneum. Diagnostic angiography confirms the mentioned diagnosis by practicing proximal angioembolization with favorable results. The indications and variants of splenic angioembolization and the role of this procedure in the nonoperative treatment of contusive splenic traumas in the conditions of antiplatelet therapy are discussed.
\end{abstract}

Keywords: splenic rupture, antiplatelet agents, interventional radiology

\section{REZUMAT}

Este prezentat cazul unui pacient în vârstă de 74 de ani, victima unei căderi accidentale, cu accident vascular cerebral sechelar aflat sub dublă medicație antiagregantă plachetară (Clopidogrel, Aspirină). Examinarea CT abdomino-pelvină cu substanță de contrast administrată intravenos evidențiază o ruptură splenică grad III AAST-OIS, cu sângerare activă şi hemoperitoneu important. Angiografia diagnostică confirmă diagnosticul menționat, practicându-se angioembolizare proximală, cu rezultate favorabile. Sunt discutate indicațiile şi variantele angioembolizării splenice şi rolul acestei proceduri în tratamentul nonoperator al traumatismelor contuzive splenice in condițiile terapiei antiagregante plachetare.

Cuvinte cheie: ruptură splenică, antiagregante plachetare, radiologie intervențională

\section{INTRODUCERE}

Creșterea speranței de viață a schimbat și distribuția pe vârstă a pacienților traumatizați. Însă, odată cu creșterea vârstei, s-a adăugat și patologia cronică a pacienților, mulți vârstnici traumatizați fiind sub tratament anticoagulant și/sau antiagregant plachetar, fapt care a determinat o nuanțare terapeutică și o provoca- 
re pentru echipa de traumatologie (medicația menționată crescând riscul hemoragiei posttraumatice).

Dacă, în cazul preparatelor de cumadină, implementarea unui protocol a determinat scăderea mortalității secundare hemoragiilor cerebrale posttraumatice cu 75\% (Ivascu), pentru terapia antiagregantă plachetară, situația este încă neclară.

\section{PREZENTAREA CAZULUI}

Pacient, în vârstă de 74 de ani, internat de urgență după o cădere accidentală.

Ultrasonografia abdominală evidențiază o imagine hipoecogenă, cu dimensiuni 94/58 mm și, caudal de aceasta, o imagine transsonică de $42 / 25 \mathrm{~mm}$ (aspecte compatibile cu o ruptură splenică) și lichid liber intraperitoneal în etajul abdominal superior $(10 \mathrm{~mm})$ și inferior (57 mm).

Radiografia toracică confirmă diagnosticul clinic: fractura coastelor IX și X stângi (fig. 1,2).

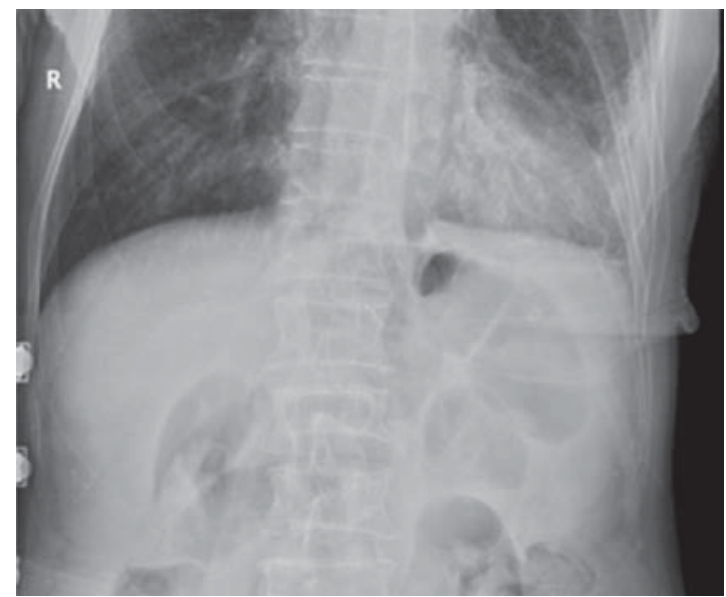

FIGURA 1. Radiografie toraco-abdominală - fractura coastelor 9, 10 stângi

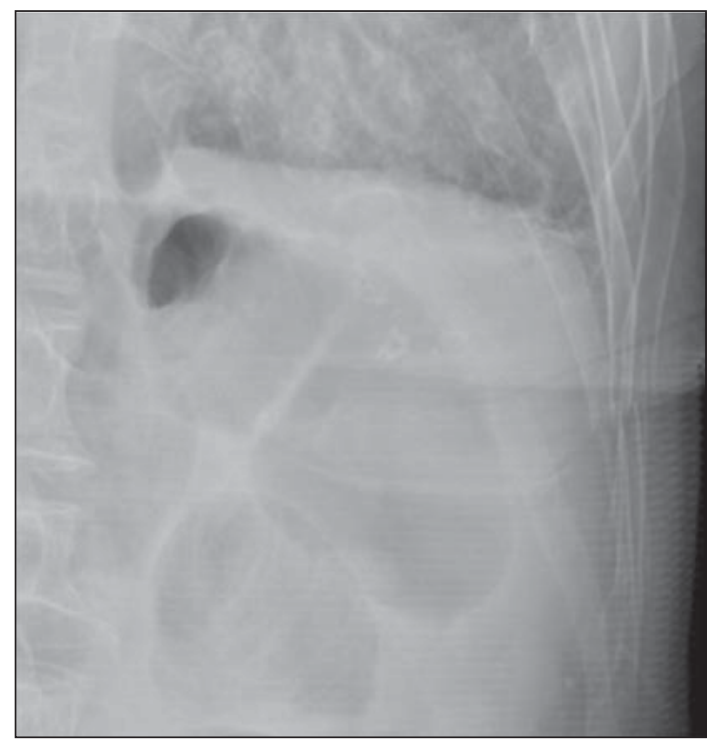

FIGURA 2. Fracturi costale 9,10 - detalii
Examinări de laborator la internare: hemoglobina 9,8 g/dl, hematocrit 30,3\%, trombocite $250.000 / \mathrm{mmc}$, leucocite 12.000/mmc, glucoza sanguină 184 mg/dl, teste de coagulare în limite normale.

Se efectuează în urgență CT abdominală cu substanță de contrast administrată intravenos, care constată: traiecte de dilacerare splenică în jumătatea inferioară, care interesează capsula polar inferior și cu extensie adiacentă hilară (fig. 3); la nivelul polului inferior, sunt prezente câteva focare cu aspect de "blush" arterial, sugestive pentru sângerare activă, situate subcapsular, și un focar cu aspect similar, cu diametrul de $8 \mathrm{~mm}$, situat juxtahilar (fig. 4); hematom voluminos perisplenic și subfrenic stâng cu diametrul axial maxim de 10 $\mathrm{cm}$; hemoperitoneu perisplenic și perihepatic cu grosime medie de $3 \mathrm{~cm}$, hemoperitoneu pelvin (fig. 5). Concluzia examinării: ruptură splenică grad III AAST-OIS, cu semne CT de sângerare activă și hemoperitoneu important.

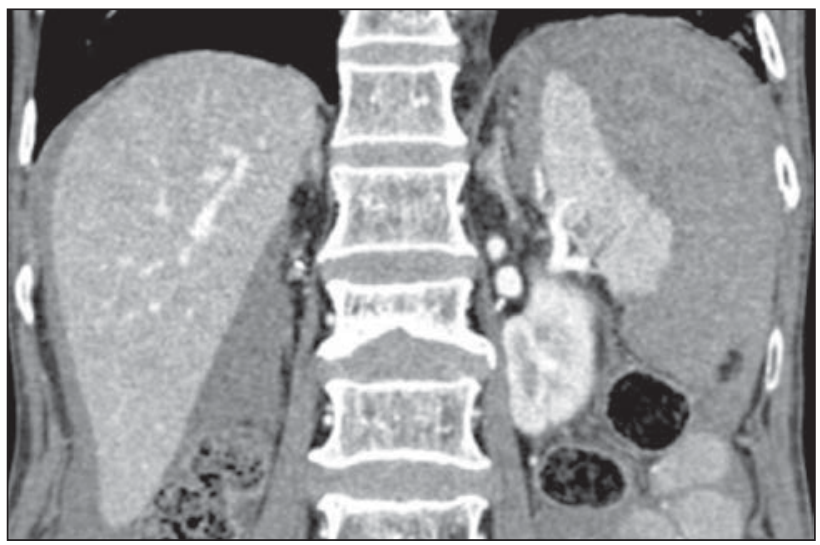

FIGURA 3. Traiecte de dilacerare splenică polare inferioare cu extensie hilară - aspect CT

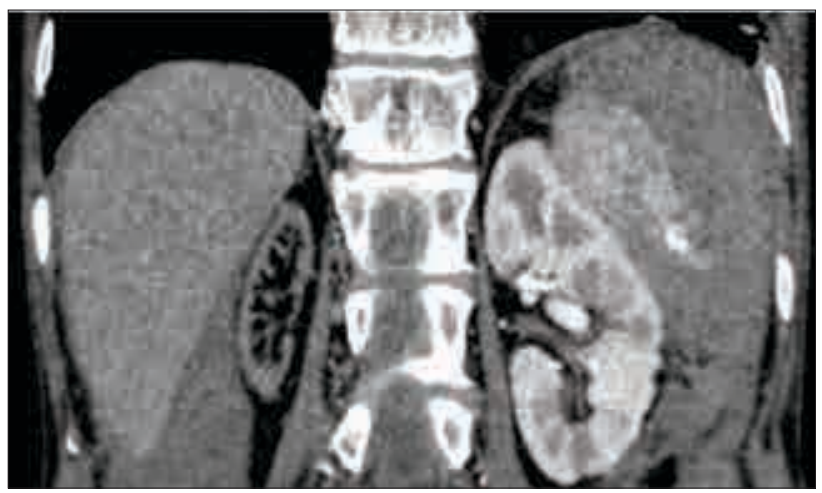

FIGURA 4. Focare cu aspect de „blush arterial” subcapsulare; focar de "blush" arterial juxtahilar - aspect CT

Pacientul fiind stabil hemodinamic și cu particularitatea unei duble terapii antiagregante plachetare, se decide efectuarea unei angiografii splenice. Timpul de la prezentarea în Departamentul de Urgență și debutul procedurii angiografice a fost de 60 de minute.

Constatări angiografice: artera splenică cu origine din artera hepatică comună (fig. 6); zonă de extravaza- 


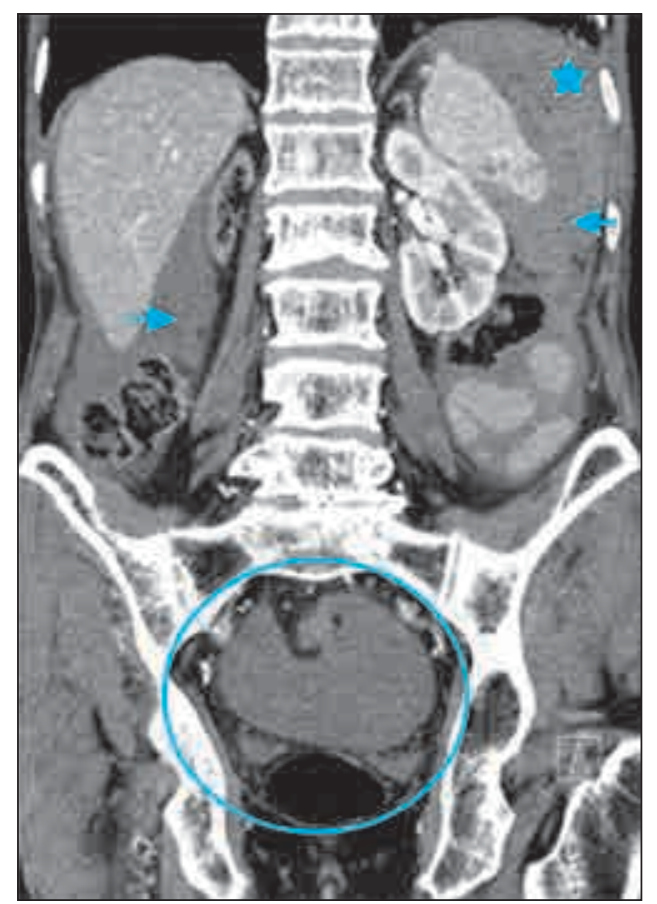

FIGURA 5. Hematom perisplenic şi subfrenic stâng (diametrul axial maxim $10 \mathrm{~cm}$ ); hemoperitoneu perisplenic $\leftarrow$ și perihepatic $\rightarrow$ (grosime medie de $3 \mathrm{~cm}$ ); hemoperitoneu pelvin $\bigcirc$

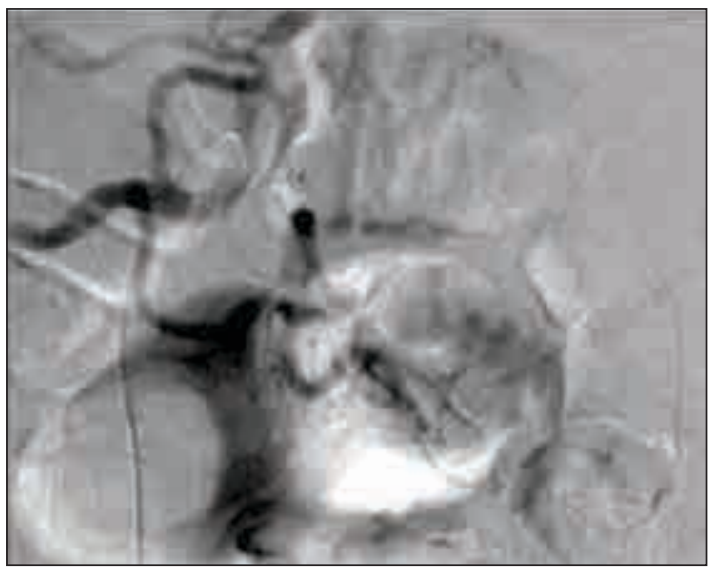

FIGURA 6. Artera splenică cu origine din artera hepatică comună

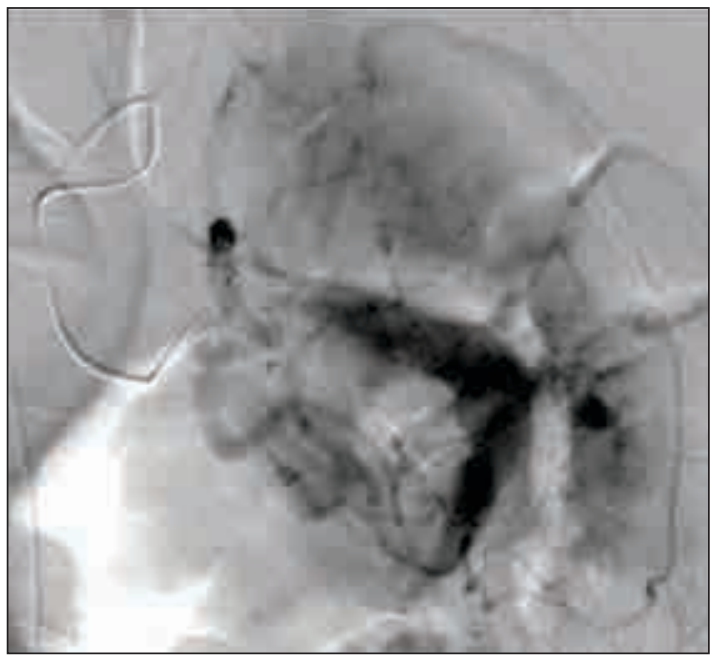

re a substanței de contrast la nivelul polului inferior (fig. 7,8); se cateterizează artera splenică cu microcateter 2,4 Fr și se embolizează proximal cu Gelitaspon ${ }^{\circledR}$, cu rezultat favorabil (fig.9).

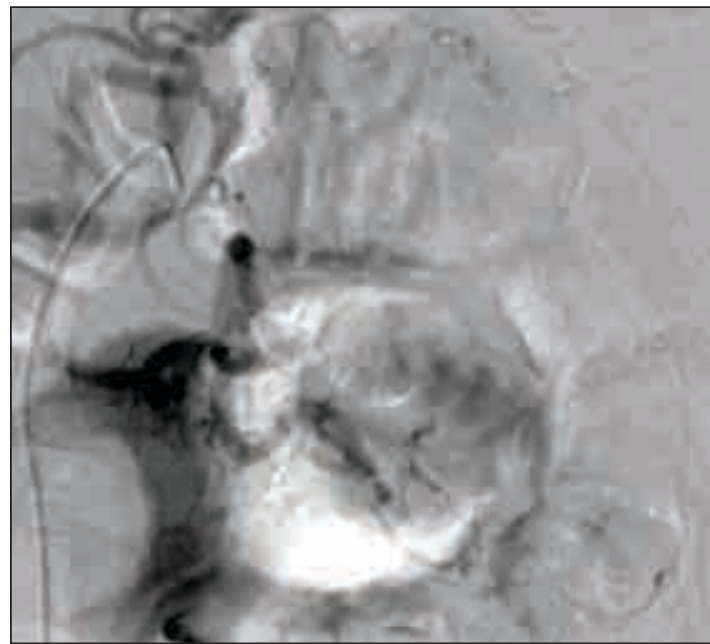

FIGURA 9. Aspect postprocedural - hemoragie oprită

Evoluția postprocedurală a fost favorabilă, pacientul fiind urmărit clinic și paraclinic (hemoleucograme repetate, ecografie) în Departamentul de Chirurgie; s-a administrat HGMM după 24 de ore de la procedura de radiologie intervențională. Perioada de spitalizare a fost de 6 zile.

\section{DISCUȚII}

Dacă, timp de zeci de ani, tratamentul leziunilor splenice posttraumatice s-a limitat la splenectomie, descoperirea importanței funcției imunologice splenice a determinat nuanțarea terapeuticii spre chirurgia conservatoare (splenorafie, splenectomie parțială/subtotală) și spre tratamentul nonoperator (TNO); angiografia intervențională s-a adăugat tratamentului nonoperator, crescând șansele prezervării splenice.

FIGURILE 7, 8. Zonă de extravazare a substanței de contrast la nivelul polului inferior splenic 
În prezent, se consideră că angiografia (diagnostică și terapeutică) face parte din TNO al traumei splenice $(2,3,4,5,6)$.

Procedurile angiografice sunt diagnostice și terapeutice, ultimele fiind efectuate cu intenția embolizării vasculare și a stopării hemoragiei. Angiografia cu substracție digitală permite un diagnostic rapid și de acuratețe, reprezentând standardul în traumatisme (2), metoda determinând reducerea timpului necesar examinării, scăderea cantității de SC utilizate și a dozei de iradiere.

AES a determinat creșterea succesului TNO prin oprirea hemoragiei splenice și prevenirea unei RIS (rupturi întârziate splenice) $(7,8)$ și a determinat reducerea riscului unei splenectomii cu peste $18 \%(9,10)$, fapt confirmat recent de Frandon (11).

Procedura este utilizată la pacienții stabili hemodinamic/ușor stabilizabili sub supraveghere chirurgicală atentă și cu posibilitatea efectuării intervenției chirurgicale în orice moment. Un avantaj deosebit al angiografiei este reprezentat de posibilitatea tratării altor leziuni vasculare concomitente (inclusiv implantări de endoproteze). Trebuie înțeles de la început că AE (angioembolizarea) este o procedură care necesită timp și un volum crescut de SC (substanță de contrast).

AES a determinat reducerea numărului de splenectomii, fiind un factor predictiv independent pentru prezervarea splenică la pacienții selecționați pentru TNO (12).

Dezavantajele metodei sunt reprezentate de: monitorizare și resuscitare dificile (în laboratorul de angiografie), necesitatea prezenței medicului de radiologie intervențională, procedură consumatoare de timp (cu riscul unei eventuale decompensări hemodinamice a pacientului), posibilitatea necesității unui volum crescut de SC (riscul nefropatiei induse de SC).

La unii pacienți, pot exista multiple surse hemoragice intrasplenice, dar, secundar vasospasmului indus de leziunea traumatică, acestea nu sunt evidențiate, fapt care poate determina resângerări postprocedurale în cazul AESD (13).

Indicațiile angiografiei splenice $(9,14,15,16)$ sunt:

- leziunile splenice grad 3, 4, 5;

- leziunile vasculare intrasplenice constatate la CT inițial, indiferent de gradul lezional;

- sângerare activă la examenul CT sau "contrast blush" la pacientul stabil hemodinamic;

- scăderea inexplicabilă a hematocritului în absența altor leziuni;

- hemoperitoneu mare.

Omert și colab. (17) consideră prezența "contrast blush" o constatare frecventă în leziunile splenice severe, aceasta nereprezentând (prin ea însăși) o indicație operatorie; este definită ca o acumulare (,focus“) a substanței de contrast localizate intraparenchimatos sau extracapsular, constatată pe imaginile tomografice inițiale sau tardive.

Toate aceste constatări l-au determinat pe Marmery (18) să propună o nouă clasificare CT a leziunilor posttraumatice splenice, care să includă sângerarea activă, fistula arterio-venoasă intrasplenică, pseudoanevrismul și leziunile vasculare ca elemente esențiale pentru aprecierea corectă a gradului lezional. Kozar și colab. (19) au realizat în anul 2018 o actualizare a clasificării AAST-OIS pentru leziunile traumatice splenice, hepatice și renale, clasificare care cuprinde aceste precizări.

Clinic, AES trebuie efectuată cât mai precoce după constatarea extravazării substanței de contrast (la examinarea CT abdominală) și înaintea apariției deteriorării hemodinamice (15).

Recomandările curente sunt:

- AES trebuie efectuată în primele 60 de minute de la internare la pacienții stabili hemodinamic care prezintă extravazarea SCIV la examinarea $\mathrm{CT}$;

- în 15-30 minute de la internare, în prezența unui hemoperitoneu mare (20).

Indicațiile AES $(10,21,22,23,24)$

Stabilitate hemodinamică la pacienții cu:

- extravazarea SC/blush/PSA/FAV la examinarea $\mathrm{CT}$;

- grad lezional splenic sever (III-V);

- hemoperitoneu mediu, mare (definit ca acumulare sanguină în ambele cadrane superioare și pelvis).

Conform opiniei lui Schurr (25) și Bhullar (26-28), prezența "contrast blush" crește de 22-24 ori riscul eșecului TNO.

Cele mai recente studii pe această temă $(28,29)$ prezintă următoarele indicații:

- "contrast blush" la examinarea CT inițială;

- grad lezional splenic IV-V stabilit la examinarea CT inițială;

- hemoperitoneu moderat;

- scăderea valorilor Hb după internare, în cursul TNO (hemoragie persistentă).

Autorii subliniază că, frecvent, indicația AES implică prezența simultană a mai multor factori menționați. Recomandarea lor este efectuarea angioembolizării în toate cazurile de rupturi splenice grad IV sau V, indiferent de prezența/absența altor constatări și utilizarea sa selectivă pentru gradele lezionale I-III doar dacă prezintă "contrast blush" sau scăderea Hb în timpul TNO.

În funcție de "pattern-ul" lezional (30), angioembolizarea splenică (AES) poate fi efectuată:

A. Distal (supraselectiv). Realizează izolarea vasului lezat, păstrează fluxul sanguin normal pentru o zonă splenică important, dar necesită un timp crescut pentru efectuare și abilități tehnice deosebite $(13,31)$. De 
asemenea, implică utilizarea unei cantități mai mari de SC (riscul nefropatiei la SC) și o doză de iradiere mai crescută $(13,32)$, proporțională cu dificultatea efectuării procedurii (22). Este indicată în leziunile vasculare localizate (trunchiere vasculară, PSA, FAV, extravazare focală) $(24,30,33)$. Realizând ocluzionarea ramurilor segmentare, care sunt artere de tip terminal, riscul infarctului splenic segmentar/abcesului poate fi crescut.

B. Proximal (trunchiul arterei splenice, distal de originea arterei pancreatice dorsale, între artera pancreatică dorsală și artera pancreatică magna, la $2 \mathrm{~cm}$ distal de artera pancreatică dorsală); se efectuează cu spirale metalice sau materiale hemostatice absorbabile (Gelfoam-Pharmacia, Kalamazoo,MI; TachoComb) și determină hemostaza prin scăderea fluxului sanguin arterial (deviat prin colaterale) (34) și a presiunii intrasplenice, fiind astfel facilitată organizarea cheagurilor și vindecarea leziunii (favorabilă pentru coagularea intrinsecă) (35); previne o RIS $(13,22)$. Viabilitatea splinei este asigurată prin circulația colaterală (ramuri din artera gastrică stângă, arterele gastro-epiploice, omentale, pancreatice, gastrice scurte), fapt demonstrat prin studiile experimentale pe animale $(36,37)$. Mecanismul de acțiune al AESP este realizat prin scăderea presiunii arteriale sistolice intrasplenice, care ajută hemostaza și permite vindecarea parenchimului splenic lezat $(30,38)$. În studiile umane, a fost constatată reducerea presiunii intrasplenice între 47 și 58\% (33). Requarth (39) a constatat după AESP o scădere a presiunii sistolice la nivelul arterei splenice distale în medie cu 67\% (semnificativ mai redusă la pacienții cu stenoza trunchiului celiac), fapt care ar putea explica sângerările întârziate postprocedurale. Fluxul sanguin splenic este menținut prin vasele colaterale, fapt care previne infarctizarea splenică, dezvoltarea abcesului splenic și menține funcția imunologică $(13,30,32,33,37)$.

Angiografia de control după AESP va evidenția ocluzia arterei splenice, cu perfuzia parenchimatoasă întârziată (realizată prin vasele colaterale) (22).

Indicațiile AESP (30):

- leziuni multiple splenice (splina "Seurat");

- leziune demonstrată la examinarea CT, dar neidentificată angiografic $(13,32)$.

Sclafani (38) consideră că această procedură este compatibilă cu menținerea funcției imune splenice și, chiar dacă este necesară intervenția chirurgicală, este facilitată splenorafia. AES proximală este mai rapidă, mai ușoară tehnic, se asociază cu un eșec mai scăzut al TNO și cu o incidență mai redusă a complicațiilor postprocedurale (abces, infarct splenic) $(4,8,17,40,41)$.

Fiind o procedură rapidă, este foarte utilă în traumatisme, când stabilitatea hemodinamică a pacientului se poate modifica rapid, și, totodată, permite efectuarea altor proceduri; reduce doza de iradiere (30).
Conform opiniei lui van der Vlies (8) și Imbrogno (32), singurul dezavantaj al AES proximale constă în faptul că, în eventualitatea unei resângerări distale, o eventuală embolizare supraselectivă este dificilă/imposibilă tehnic, fiind necesară embolizarea prin colaterale pentru efectuarea unei AESD. Nu s-au constatat diferențe semnificative referitoare la eficacitatea acestor două tehnici (42).

C. Combinat. Decizia de efectuare a AESP după AESD depinde de pattern-ul lezional, starea pacientului, practicile locale și preferința radiologului intervenționist (30). În prezența unor leziuni multifocale și leziune de ram splenic obiectivată angiografic, AESP se va efectua imediat după AESD; în situația unei leziuni unice cu corelare angiografică, se indică doar AESD (22), păstrându-se AESP pentru o eventuală resângerare.

Explicația acestei indicații: unele leziuni vasculare nu pot fi identificate la angiografia inițială și pot determina resângerări după dispariția vasospasmului $(43,44)$.

Totuși, acest abord combinat determină un procent crescut de complicații $(58,8 \%)$ comparativ cu AESP $(18,2 \%)$ sau AESD $(28,7 \%)(23)$.

Vârsta peste 65 de ani reprezintă un factor de gravitate la pacienții traumatizați (45), iar tratamentul anticoagulant cronic asociat crește riscurile. Cauza majoră de morbiditate și mortalitate la acești pacienți este reprezentată de căderile accidentale (90\%) (46), iar, conform estimării Center for Disease Control and Prevention (2011), o persoană din trei $\geq 65$ ani a suferit o cădere, iar, la 20-30\% dintre aceste cazuri, leziunile au fost moderate și severe (47), pentru leziunile severe mortalitatea fiind peste $50 \%(46)$.

Cauzele acestei mortalități crescute sunt reprezentate de hemoragia cerebrală posttraumatică, leziunile ortopedice și leziunile viscerale toraco-abdominale. Pacienții traumatizați cu terapie cronică antiagregantă plachetară (Aspirină, Clopidogrel) prezintă o mortalitate crescută (1) pentru toate aceste cauze (47).

Analiza lui Boltz (47) a ajuns la o concluzie surprinzătoare: la pacienții $\geq 65$ de ani cu căderi accidentale, cele mai frecvente leziuni au fost: gastrice, duodenale, entero-colonice, pancreatice, hepatice, splenice și renale. Morbiditatea la cazurile cu tratament anticoagulant oral (ACO) a fost statistic semnificativ crescută pentru ARDS, IRA (insuficiență renală acută), sindrom de compartiment abdominal, stop cardiac, infarct miocardic acut, pneumonie și șoc septic, majoritatea prezentând complicații multiple, iar probabilitatea decesului a crescut cu $180 \%$.

Terapia anticoagulantă orală este administrată în principal în patologia cardiovasculară (cel mai frecvent, fibrilația atrială), riscurile fiind general acceptate. Analiza lui Boltz (47) a evidențiat că leziunile tractului gastro-intestinal apar cel mai frecvent la pacienții cu 
căderi accidentale cu tratament ACO, urmând, ca frecvență, leziunile organelor parenchimatoase abdominale, fără a se constata o legătură cu tipul medicației anticoagulante orale administrate; mai mult, medicația ACO este profilactică pentru TVP, dar crește riscul pentru embolia pulmonară.

Ivascu (1) a constatat că pacienții sub tratament antiagregant plachetar (Aspirina, Clopidogrel sau ambele) cu leziuni cerebrale hemoragice posttraumatice au prezentat leziuni mai severe și o mortalitate crescută comparativ cu cei fără terapie antiagregantă plachetară, fapt subliniat și de Wong (48).

Riscul unei leziuni splenice secundare unei căderi accidentale este mult mai crescut la pacientul cu terapie ACO (1,8\% vs. $0,4 \%)(47)$.

Smalls (49) a studiat impactul tulburărilor de coagulare preexistente (boala von Willebrand, hemofilia, coagulopatia secundară administrării de Warfarină sau Clopidogrel) asupra evoluției traumatismelor contuzive splenice. Analiza cazurilor (58.896 traumatisme contuzive splenice) a evidențiat că doar $2 \%$ (1.137) dintre pacienți au prezentat o tulburare de coagulare preexistentă, $44 \%$ având $\geq 65$ de ani. Opțiunile terapeutice au fost: TNO (64\%), AES (7\%), splenectomie (27\%) și AES urmată ulterior de splenectomie (2\%). Eșecul TNO a fost mai frecvent, autoarea constatând existența unei tendințe de temporizare/întârziere a intervenției chirurgicale (7-10 ore), interval necesar corectării coagulopatiei sau fiind motivat de o resângerare.

Liagkos și colab. (50) subliniază importanța corectării coagulopatiei induse medicamentos constatând că leziunile contuzive splenice și hepatice (grad AAST OIS $\leq 3$ ) la pacienții stabili hemodinamic pot fi tratate nonoperator în siguranță; tipul medicației antiagregante plachetare nu pare să influențeze evoluția acestora.

Părerea generală este că, la pacienții cu tratament cronic cu Clopidogrel, intervențiile chirurgicale elective trebuie să fie efectuate după 7 zile de oprire a adminis- trării medicamentului $(51,52)$; în cazul chirurgiei de urgență, se indică efectuarea intervenției fără întârziere, cu atenție deosebită la hemostaza intraoperatorie și accesul rapid la masă trombocitară, dacă este necesar.

„Alianța terapeutică“ (2) între chirurgul de traumă și radiologul intervenționist permite standardul optim de îngrijire la pacienții care necesită $A E$, iar încorporarea acestuia în echipa de traumatologie este o necesitate.

\section{CONCLUZII}

Dezvoltarea medicinei a determinat creșterea speranței de viață și, în consecință, în Departamentul de Urgență se prezintă un număr crescut de pacienți vârstnici traumatizați. Vârsta $\geq 55$ de ani a reprezentat inițial un factor predictiv al eșecului tratamentului nonoperator; ulterior, a devenit un factor discutabil în opinia diverșilor chirurgi de traumatisme, dar au apărut modificări semnificative. Astfel, vârsta $\geq 55$ de ani a avansat la 65 de ani, un număr semnificativ de pacienți fiind sub tratament anticoagulant cronic (cumarinic anticoagulante antivitamina $\mathrm{K}$ ), antiagregant plachetar (acid acetilsalicilic, clopidogrel, trifusal). La acestea, se adaugă noile anticoagulante orale (dabigatran, rivaroxaban, edoxaban, apixaban), care complică evoluția tratamentului nonoperator al leziunilor organelor parenchimatoase. În această situație, radiologia intervențională are o indicație majoră și o valoare deosebită terapeutică. "Chirurgia cu un cateter" permite rezolvarea rapidă, miniinvazivă a unei situații critice (vârstnic sub tratament anticoagulant cu sângerare activă splenică) și continuarea reechilibrării concomitente a pacientului, cu riscuri scăzute comparativ cu chirurgia clasică. Se poate afirma că radiologia intervențională face parte din "standardul de aur" al diagnosticului și tratamentului leziunilor contuzive ale organelor parenchimatoase.

Conflict of interest: none declared Financial support: none declared

\section{BIBLIOGRAFIE}

1. Ivascu FA, Howells GA, Junn FS, Bair HA, Bendick PJ, Janczyk RJ. Predictors of mortality in trauma patients with intracranial hemorrhage on preinjury aspirin or clopidogrel. J Trauma. 2008 Oct; 65(4):785-8.

2. Bauer JR, Ray CE. Transcatheter arterial embolization in the trauma patient: a review. Seminars in Interventional Radiology. 2004; 21:11-22.

3. Pryor JP, Braslow B, Reilly MP, Gullamondegi O, Hedrick JH, Schwab CW. The evolving role of interventional radiology in trauma care. J Trauma. 2005;59:102-104.

4. Smith HE, Biffl WL, Majercik SD, Jednacz J, Lambiase R, Cioffi WG. Splenic artery embolization: Have we gone too far? J Trauma. 2006;61:541-546.

5. Wei B, Hemmila MR, Arbabi S, Taheri PA, Wahl WL. Angioembolization reduces operative intervention for blunt splenic injury. J Trauma. 2008;64:1472-1477.

6. Dehli T, Bågenholm A, Trasti NC, Monsen SA, Bartnes K. The treatment of spleen injuries: a retrospective study. Scand J Trauma Resusc Emerg Med. 2015.29;23:85.

7. van der Vlies $\mathrm{CH}$, van Delden OM, Punt BJ, Ponsen KJ, Reekers JA, Goslings JC. Literature review of the role of ultrasound, computed tomography, and transcatether arterial embolization for the treatment of traumatic splenic injuries. Cardiovasc Intervent Radiol. 2010;33:1079-1087.

8. van der Vlies $\mathrm{CH}$, Hoekstra J, Ponsen KJ, Reekers JA, van Delden OM, Goslings JC. Impact of splenic artery embolization on the success rate of nonoperative management for blunt splenic injury. Cardiovasc Interv Radiol. 2012;35:76-81.

9. Haan JM, Bochicchio GV, Kramer N, Scalea TM. Nonoperative management of blunt splenic injury: a 5-year experience. J Trauma. 2005;58(3):492-498.

10. Gaarder C, Dormagen JB, Eken T, Skaga NO, Klow NE, Pillgram-Larsen J, Buanes T, Naess PA. Nonoperative management of 
splenic injuries: improved results with angioembolization. J Trauma. 2006;61:192198.

11. Frandon J, Rodiere M, Arvieux C, Michoud $M$, Vendrell A, Broux C, Sengel C, Bricault I, Ferretti G, Thony F. Blunt splenic injury: are early adverse events related to trauma, nonoperative management, or surgery? Diagn Interv Radiol. 2015;21(4):327-333.

12. Carlotto JRM, Lopes-Filho $G$ de Jesus, Colleoni-Neto R. Main controversies in the nonoperative management of blunt splenic injuries. Arq Bras Cir Dig. 2016;29:60-64.

13. Hoppe H, Kos S. Splenic Artery Embolization: Proximal or Distal? A review of when proximal or distal embolization should be used, optimal technique, and results of studies evaluating outcomes. Endovascular Today. 2018;17(4):73-76.

14. Dent D, Alsabrook G, Erickson BA, Myers J, Wholey M, Stewart R, Root H, Ferral H, Postoak D, Napier D, Pruitt BA Jr. Blunt splenic injuries: high nonoperative management rate can be achieved with selective embolization. J Trauma. 2004;56:1063-1067.

15. Wu SC, Chow KC, Lee KH, Tung CC, Yang AD, Lo CJ. Early selective angioembolization improves success of nonoperative management of blunt splenic injury. Am Surg. 2007;73:897-902.

16. Sabe AA, Claridge JA, Rosenblum DI, Lie K Malangoni MM. The effects of splenic artery embolization on nonoperative management of blunt splenic injury: a 16-year experience. J Trauma. 2009;67:565-572.

17. Omert LA, Salyer D, Dunham CM, Porter J, Silva A, Protetch J. Implications of the "contrast blush" finding on computed tomographic scan of the spleen in trauma. $J$ Trauma. 2001;51:272-278.

18. Marmery $\mathrm{H}$, Shanmuganathan $\mathrm{K}$, Alexander MT, Mirvis SE. Optimization of selection for nonoperative management of blunt splenic injury: comparison of MDCT grading systems. AJR Am J Roentgenol. 2007;189:1421-1427.

19. Kozar RA, Crandall M, Shanmuganathan K, Zarzaur B, Coburn M, Cribari C, Kaups K, Schuster K, Tominaga GT; AAST Patient Assessment Committee. Organ injury scaling 2018 update: Spleen, liver, and kidney [published correction appears in $\mathrm{J}$ Trauma Acute Care Surg. 2019 Aug;87(2):512]. J Trauma Acute Care Surg. 2018; 85(6):1119-1122.

20. van der Cruyssen F, Manzelli A. Splenic artery embolization: technically feasible but not necessarily advantageous. World Journal of Emergency Surgery. 2016; 11(1):47

21. Fu CY, Wu SC, Chen RJ, Chen YF, Wang YC, Huang HC, Huang JC, Lu CW, Lin WC. Evaluation of need for operative intervention in blunt splenic injury: intraperitoneal contrast extravasation has an increased probability of requiring operative intervention. World J Surg. 2010;34:27452751.
22. McCabe S, Maddineni S, Marini C, Rozenblit G. Vascular and interventional radiology in blunt abdominopelvic trauma Institutional practice and review of the literature. J Trauma Treat. 2016;5:324.

23. Rong JJ, Liu D, Liang M, Wang QH, Sun JY, Zhang QY, Peng CF, Xuan FQ, Zhao LJ, Tian XX, Han YL. The impacts of different embolization techniques on splenic artery embolization for blunt splenic injury: a systematic review and meta-analysis. Mil Med Res. 2017 May 30;4:17.

24. Martin JT, Hulsberg PC, Soule E, Shabandi $\mathrm{M}$, Matteo J. Welcome to the new era: a completely wireless interventional procedure. Cureus. 2018;10:e3337:

25. Schurr MJ, Fabian TC, Gavant M, Croce MA, Kudsk KA, Minard G, Woodman G, Pritchard FE. Management of blunt splenic trauma: computed tomographic contrast predicts failure of nonoperative management. J Trauma. 1995;39:507-513.

26. Bhullar IS, Frykberg ER, Siragusa D, Chesire D, Paul J, Tepas JJ III, Kerwin AJ. Selective angiographic embolization of blunt splenic traumatic injuries in adults decreases failure rate of nonoperative management. J Trauma. 2012; 72:1127-1134

27. Bhullar IS, Frykberg ER, Tepas JJ III, Siragusa D, Loper T, Kerwin AJ. At first blush: Absence of computed tomography contrast extravasation in grade IV or V adult blunt splenic trauma should not preclude angioembolization. J Trauma. 2013; 74:105-112

28. Bhullar IS, Tepas JJ III, Siragusa D, Loper T, Kerwin A, Frykberg ER. To nearly come full circle: Nonoperative management of high-grade IV-V blunt splenic trauma is safe using a protocol with routine angioembolization. Journal of Trauma and Acute Care Surgery. 2017;82:657-664.

29. Alamri Y, Moon D, Ah Yen D, Wakeman C, Eglinton T, Frizelle F. Ten-year experience of splenic trauma in New Zealand: the rise of nonoperative management. NZMA. 2017; 130:11-18.

30. Quencer KB, Smith TA. Review of proximal splenic artery embolization in blunt abdominal trauma. CVIR Endovasc. 2019 Mar 18;2(1):11.

31. Harbrecht BG. Is anything new in adult blunt splenic trauma? The American Journal of Surgery. 2005;190:273-278.

32. Imbrogno BF, Ray CE. Splenic artery embolization in blunt trauma. How I do it. Semin Intervent Radiol. 2012;29:147-149.

33. Bessoud B, Denys A. Main splenic artery embolization using coils in blunt splenic injuries: effects on the intrasplenic blood pressure. Eur Radiol. 2004 Sep; 14(9):1718-9.

34. Yip H, Skelley A, Morphett L, Mathew J, Clements W. The cost to perform splenic artery embolisation following blunt trauma: Analysis from a level 1 Australian trauma centre. Injury. 2020 Sep 19;S00201383(20):30737-3.
35. Preece SR, Schriber SM, Choudhury KR, Suhocki PV, Smith TP, Kim CY. Coil embolization of the splenic artery: impact on splenic volume. J Vasc Interv Radiol. 2014;25(6):859-865.

36. Hagiwara A, Yukioka T, Ohta S, Nitatori T, Matsuda H, Shimazaki S. Nonsurgical management of patients with blunt splenic injury: efficacy of transcatheter arterial embolization. AJR. 1996;167:159-166.

37. Zmora O, Kori Y, Samuels D, Kessler A, Schulman $\mathrm{Cl}$, Klausner JM, Soffer D. Proximal splenic artery embolization in blunt splenic trauma. European Journal of Trauma and Emergency Surgery. 2009;35:108-114.

38. Sclafani SJA, Shaftan GW, Scalea TM, Patterson LA, Kohl L, Kantor A, Herskowitz MM, Hoffer EK, Henry S, Dresner LS, Wetzel W . Nonoperative salvage of computed tomography-diagnosed splenic injuries: utilization of angiography for triage and embolization for hemostasis. J Trauma. 1995;39:818-827.

39. Requarth JA, Miller PR. The splenic artery stump pressure is affected by arterial anatomy after proximal embolotherapy in blunt splenic injury. Journal of Trauma and Acute Care Surgery. 2012;73:1221-1224.

40. Haan JM, Marmery H, Shanmuganathan K, Mirvis SE, Scalea TM. Experience with splenic main coil embolization and significance of new or persistent pseudoaneurysm: reembolize, operate or observe. J Trauma. 2007;63:615-619.

41. Killeen KL, Shanmuganathan K, BoydKranis R, Scalea TM, Mirvis SE. CT findings after embolization for blunt splenic trauma. $J$ Vasc Interv Radiol. 2001;12:209-214.

42. Rasuli P, Moosavi B, French GJ, Petrcich W, Hammond I. Splenic artery embolization in blunt trauma: a single-center retrospective comparison of the use of Gelatin sponge versus coils. AJR. 2017;209:W382-W387.

43. Norotsky MC, Rogers FB, Shackford SR. Delayed presentation of splenic artery pseudoaneurysms following blunt abdominal trauma: case reports. J Trauma. 1995 Mar; 38(3):444-7.

44. Nance FC, Nance ML. Delayed presentation of splenic artery pseudoaneurysms following blunt abdominal trauma. J Trauma. 1995 Sep;39(3):620-1.

45. Ohmori T, Kitamura T, Tanaka K, Saisaka Y, Ishihara J, Onishi H, Nojima T, Yamamoto K, Matsumoto T, Tokioka T. Bleeding sites in elderly trauma patients who required massive transfusion: a comparison with younger patients. Am J Emerg Med. 2016 Feb;34(2):123-7.

46. Pieracci FM, Eachempati SR, Shou J, Hydo LJ, Barie PS. Use of long-term anticoagulation is associated with traumatic intracranial hemorrhage and subsequent mortality in elderly patients hospitalized after falls: analysis of the New York State Administrative Database. J Trauma. 2007 Sep;63(3):519-24.

47. Boltz MM, Podany AB, Hollenbeak CS, Armen SB. Injuries and outcomes associated with traumatic falls in the elderly 
population on oral anticoagulant therapy. Injury. 2015 Sep;46(9):1765-71.

48. Wong DK, Lurie F, Wong LL. The effects of clopidogrel on elderly traumatic brain injured patients. J Trauma. 2008 Dec;65(6):1303-8.

49. Smalls N, Obirieze A, Ehanire I. The impact of coagulopathy on traumatic splenic injuries. Am J Surg. 2015 Oct;210(4):724-9.
50. Liagkos G, Spyropoulos C, Chouliaras C, Tsourouflis G, Kouraklis G, Vagianos CE. Management of blunt hepatic and splenic injuries (grade $\leq$ III) in patients receiving antithrombotic therapy. Ann Ital Chir. 2019;90:421-426.

51. Ozao-Choy J, Tammaro Y, Fradis M, Weber $\mathrm{K}$, Divino CM. Clopidogrel and bleeding after general surgery procedures. Am Surg. 2008 Aug;74(8):721-5.

52. Chernoguz A, Telem DA, Chu E, Ozao-Choy J, Tammaro Y, Divino CM. Cessation of clopidogrel before major abdominal procedures. Arch Surg. 2011 Mar;146(3):334-9. 